\title{
O SERTÃO VIRA MAR NO «CONTRA-FLUXO» REGIONAL
}

\author{
Maria Érica de Oliveira Lima \\ Bacharel em Comunicação Social - Jornalismo (PUC-Campinas) \\ Mestra em Comunicação (Umesp). Doutoranda em Comunicação Social \\ (Umesp e UFP)

\section{INTRODUÇÃO} \\ Para entender a natureza da pós-modernidade, o processo \\ de globalização e o avanço das novas tecnologias, deveremos dar \\ ênfase ao desenvolvimento dos meios de comunicação e seu \\ impacto. Assim, como explica Thompson (1999, p. 13):
}

Nós só poderemos entender o impacto social do desenvolvimento das novas redes de comunicação e do fluxo de informação, se pusermos de lado a idéia intuitivamente plausível de que os meios de comunicação servem para transmitir informações e conteúdo simbólico a indivíduos cujas relações com os outros permanecem fundamentalmente inalteradas (...). O uso dos meios de comunicação implica a criação de novas formas de ação e de interação no mundo social, novos tipos de relações sociais e novas maneiras de relacionamento do indivíduo com os outros e consigo mesmo.

Portanto, o desenvolvimento dos meios de comunicação fez com que o poder tomasse várias formas, inclusive, numa escala visível e efetivamente global. Na verdade, esta circunstância faz parte do complexo processo de globalização cujas origens remontam desde o século XIX. Neste ponto, a vida social que é feita de indivíduos, da qual possue fins e objetivos variados, acaba por ser modificada significativamente. São várias circunstâncias que proporcionam este fenômeno de desenvolvimento, inclusive, proporcionando aos diferentes indivíduos, diferentes oportunidades e condições sociais, culturais, e também, pessoais. Como diria Pierre Bordieu, estas circunstâncias podem ser conceituadas como «Campos de Interação», ou seja, como explica o próprio Thompson (1999, p. 21): 
os indivíduos se situam em diferentes posições dentro destes campos, dependendo do tipo e da quantidade de recursos disponíveis para eles. Em alguns casos estas posições, quando institucionalizadas, adquirem uma certa estabilidade - isto é, tornam-se parte de um conjunto relativamente estável de regras, recursos sociais. As instituições podem ser vistas como determinados conjuntos de regras, recursos e relações com certo grau de durabilidade no tempo e alguma extensão no espaço, e que se mantêm unidas com o propósito de alcançar alguns objetivos globais. As instituições definem a configuração dos campos de interação pré-existentes e, ao mesmo tempo, criam novas posições dentro deles, bem como novos conjuntos de trajetórias de vida para os indivíduos que os ocupam.

Neste prisma de desenvolvimento e globalização, eis que surge um novo projeto de comunicação: rádio via-satélite. Conseqüentemente, modificando os «campos de interação» dos quais Pierre Bordieu demonstra. Esses campos são totalmente influenciados e modificados pelos meios de comunicação, neste caso, o rádio via-satélite, que por tabela, modifica as relações sociais, pessoais e institucionais, ou seja, como o exemplo de que através de avançados recursos tecnológicos e conquista de mercado consumidor de bens culturais, pode-se surgir além de um novo pólo de produção cultural, também, pode inverter o fluxo de grupos de mídia regional, o que denominamos, neste estudo, de «contra-fluxo». Ou seja, no Brasil concentram-se grupos midiáticos na região Sudeste, mas precisamente, eixo Rio-São Paulo. Agora, evidenciamos surgimento de novas empresas, de caráter regional e com perspectivas nacionais, que transmitem sua programação para outros estados do país. Exemplos: emissora de rádio, Somzoom Sat (CE), Estação Sat (PE) e Tropical Sat (BA); as TV’s Amazon Sat (AM) e TV Diário (CE), todas utilizando do recurso do satélite e sendo transmitidas do Norte-Nordeste. Esse fenômeno pode ser explicado por Martín Barbero quando nos aponta para a evolução das tecnologias:

El número de emisoras de televisión se multiplicó - de 205 en 1970 pasó a 1459 en 1988-, Brasil y México se dotaron de satélites 
proprios, la radio y la televisión abrieron enlaces mundiales vía satélite, se implantaron redes de datos, fibra óptica, antenas parabólicas, TVCable, y se establecieron canales regionales de televisión (Martín Barbero, 2004, p. 2).

O «contra-fluxo» de grupos de mídia regional se dá no momento em que a produção/informação começa surgir de uma outra determinada natureza e/ou região, ao contrário daquela já estabelecida. Por exemplo, no Brasil, as informações surgem no eixo Rio-São Paulo, onde se concentram as maiores emissoras de rádio, TVs, revistas, editoras, cinemas, produtoras, agências de publicidade \& propaganda, gravadoras de CDs, provedores de Internet, ou seja, todo o campo midiático, gerando informações e notícias que penetram nos campos de interação. O contrário das informações geradas, longe deste mapa midiático, do eixo Rio-São Paulo, se dando em outra região, como por exemplo, o Nordeste do país, se disseminando, configura-se um contra-fluxo de empresas midiáticas que apostam no mercado regional e, muitas vezes, nacional. Também porque não falarmos em extensão internacional? A TV Diário, do Sistema Verdes Mares de Comunicação (CE), transmite por satélite para países do Mercosul.

Para entendermos o processo de surgimento e evolução de (novos) grupos de mídia regionais, nacionais e até internacionais, é preciso compreender as mudanças econômicas e políticas que o Brasil vem passando ao longo dos anos. Anamaria Fadul aponta que o processo de internacionalização da mídia, de grupos já consolidados nacionalmente, só aconteceu por conta de uma abertura no campo econômico:

O processo de internacionalização dos principais grupos de mídia no Brasil nos anos 90 está relacionado, de um lado, com as grandes mudanças na economia e política que levaram a uma abertura do mercado brasileiro à economia internacional e, por outro lado, com o surgimento da TV por assinatura e o processo de desregulamentação da informática e das telecomunicações (Fadul, 1998, p. 81). 
Este artigo visa demonstrar, registrar e ainda mais, arriscar, para uma reflexão de que temos um «contra-fluxo» de empresas midiáticas no Brasil, em relação às empresas de mídia do eixo Rio-São Paulo? Os exemplos da Somzoom Sat e TV Diário demonstram a capacidade de se fazer mídia, ao contexto regional, nacional e muitas vezes, internacional, sem serem afiliadas e retransmissoras de nenhum outro grupo predominante? O que nos diz as Ciências da Comunicação sobre estes fenômenos?

Nas Teorias da Comunicação, quando utilizamos os termos «fluxo» e «contra-fluxo» da informação, comunicação, notícia, etc. nos indicam os estudos da década de 70/80 em que pesquisadores analisavam a dependência midiática da América Latina, em relação a órgãos, grupos de mídia (TV, rádio, agências noticiosas, etc.) dos países do primeiro mundo. Neste sentido, adotamos estes termos, que necessariamente não apresentam os mesmos conceitos do cenário anterior, da América Latina; mas que vai nos apontar para uma reflexão e, talvez, uma possibilidade de apresentarmos, no futuro, outros conceitos em relação ao surgimento dos fenômenos de grupos de mídia regional/nacional/internacional que nascem fora do eixo Rio-São Paulo. Tudo isso vem ao encontro de novos estudos e análises da comunicação. É esse o risco deste artigo.

Os projetos da Somzoom Sat e TV Diário vêm tentar consolidar como emissoras, seja Rádio ou TV, de identidade regional, nordestina, porém com abrangência nacional e muitas vezes, internacional, a nos revelar mudanças no cenário midiático brasileiro. E mais, que as estratégias empresariais dos grupos regionais, através da programação, possam está contribuindo para uma nova produção da indústria cultural? No caso da Somzoom Sat:

(...) surge à estratégia empresarial que, baseada na força do meio rádio e utilizando-se de elementos da cultura popular nordestina e da mais avançada tecnologia, a Rede Somzoom Sat: a rádio mais popular do Brasil. Por trás desse fenômeno está o empresário Emanoel Gurgel, que de dono de uma fabriqueta de camisetas no começo da década de 90, passou a trabalhar com bandas de forró e montou um negócio que fatura atualmente U\$ 3 milhões mensais, o 
ano inteiro, e o tornou o maior empresário da indústria cultural do Nordeste (Pedroza, 2001).

Compreender o processo, que chamamos, ousadamente, de «contra-fluxo» de grupos de mídia no Brasil, exige-se, em primeiro momento, contínuas reflexões. Além do registro para se abrir ao debate e diálogo. Concordamos com a pesquisadora Fadul (1998, p.86) quando nos diz: «(...) existe um grande potencial de transformações dos grupos de mídia com as próximas concessões de TV por assinatura. Espera-se o surgimento de outros grupos nessa área». Portanto, arrisco-me no registro e reflexão!

\section{O PERFIL DA SOMZOOM SAT}

Somzoom Sat é uma empresa que possui a estação satélite digital, Rede Somzoom Sat, que gera sinal codificado para todo o Brasil, via BS1 (Brasil Sat 1) 24 h por dia. A Rede Somzoom faz parte das novas tecnologias aplicada à mídia, além claramente, do processo de globalização que vai determinar o «contra-fluxo» de um grupo de mídia regional, enquanto negócio econômico e também cultural. A empresa está localizada em Fortaleza (CE), portanto, apresentando como sendo a primeira emissora de rádio com programação via-satélite a partir do Nordeste.

A emissora, além da proposta de uma identidade tipicamente nordestina - ressaltando em sua programação a cultura segmentada e industrial do Nordeste, através do forró -, também aponta para o cenário nacional, mas carregando uma programação tipicamente regional. No Brasil, não há condições de grupos regionais vir a apresentar uma dimensão nacional, enquanto formato, conteúdo, aceitação, distribuição. Grupos regionais possuem alcance nacional, enquanto presença física em algumas partes do território, mas buscam comunidades específicas que os identifiquem. Isso mostra a riqueza e diferenças culturais que temos. É o caso da Rede Somzoom Sat e TV Diário. Elas estão presentes em vários estados do país, mas são apreciadas e compreendidas pela população que representam a identidade regional de origem. 
Assim explica Fadul (1998, p. 83), «devido à extensão do país, se poderia dizer que na história da mídia brasileira são poucos os grupos que se preocupam em buscar essa dimensão verdadeiramente nacional». Para isso, os grupos de mídia regionais, das quais estamos falando, não buscam montar um formato de programação que venha ser nacional, e sim regional, mas que atinja, em muitos momentos, a comunidade espalhada pelo país afora.

A Somzoom Sat é um grupo que pertence ao empresário Emanuel Gurgel de Queiroz, que integra, ainda, um conjunto de outros segmentos:

- Rede Somzoom Sat (cabeça de rede, emissora via-satélite);

- Somzoom Stúdio (selo fonográfico, produção e gravações de CD’s);

- Editora Passaré (Edita todas as músicas gravadas na Somzoom);

- Bandas de forró: a principal, «Mastruz com Leite»;

- Fábrica de amplificadores Mastruz com Leite (som de alta potência - para shows);

- Zoom Promoções (produz eventos, promovem artistas regionais);

- Casas de shows de forró, em Fortaleza (CE): («Parque do Vaqueiro», «Casa do forró», «Vila forró»).

O nome empresarial do Grupo de Emanuel Gurgel, em registro, na Junta Comercial do Ceará é Somzoom Gravações e Edições Musicais Ltda. De caráter sociedade limitada, tem como data de início das atividades em 01 de dezembro de 1991. Engloba várias atividades econômicas:

edições de periódicos; execução de serviços gráficos; comércio varejista de material elétrico, eletrônico, aparelhos e equipamentos para comunicação, peças e acessórios; comércio varejista de instrumentos musicais e acessórios discos e fitas magnéticos e gravados; comércio varejista de artigos importados; reparação, manutenção e instalação de máquinas e de aparelhos; promoção e produção de espetáculos artísticos, culturais e esportivos; exploração de locais e instalação 
para diversão, recreação e prática de esportes; serviços de publicidade e propaganda; serviços auxiliares e produção de película cinematográficas e fitas para vídeo; serviços de locação e arrendamento de máquinas, equipamentos e instalações. (Junta Comercial do Ceará, 2003).

A SomZoom também dispõe 24 horas de uma estação móvel Hy way que lhe possibilita transmitir de qualquer ponto do mundo que tenha a cobertura do satélite, com a mesma qualidade do estúdio. Esse estúdio móvel é usado, freqüentemente, nas transmissões de eventos, como por exemplo das vaquejadas organizadas pelo próprio grupo. Nestas vaquejadas se encontram locutores que fazem reportagens locais, com o objetivo de transformá-las em informações, transmitidas pela Rede SomZoom.

A Rede Somzoom Sat tem uma programação que «abrange todos os ritmos musicais brasileiros», em preferência para o forró, ocupando mais de $70 \%$ da programação (Rede Somzoom Sat, www.somzoom.com/2001).

Hoje a Rede Somzoom conta com uma forte concorrente: Estação Sat. No dia 09 de março de 2001, surgiu a primeira transmissão da Rede Estação Sat, localizada em Recife (PE), bairro São José, área central da capital. Pertencente ao empresário João Florentino, conhecido como o «maior distribuidor de discos do Brasil, dono da extinta rede de lojas Aky Discos», a emissora tem o objetivo de vender discos através da programação veiculada pela Estação Sat:

Com a extinção da rede de lojas Aky Discos, o João Florentino resolveu vender discos através dessa nova emissora. Ele é dono do selo Polymusic com dezenas de artistas contratados, basicamente, dos gêneros de forró e brega. Seguindo os passos do Emanuel Gurgel, dono da Somzoom Sat, a primeira rede de rádios sediada no Nordeste, que usou a rede para vender discos das bandas de forró como Mastruz com leite e companhia (Lima, 2003).

Atualmente, a Estação Sat conta com 42 emissoras afiliadas à sua programação, espalhadas pelos Estados do Nordeste: 
Pernambuco, Paraíba, Rio Grande do Norte, Piauí, Alagoas, Ceará, Maranhão, Bahia; no Norte: Pará; Centro-Oeste, Tocantis (Estação Sat, www.estacaosat.com.br/2003).

O grupo Estação Sat, como podemos também denominar, é constituído de um «grande estúdio de gravação, um dos mais bem equipados do Nordeste; um selo, Polymusic; uma distribuidora, Estação CD; uma grande loja, Akyvídeo; uma rede evangélica de rádio, a Canãa, e mais uma emissora pop que ainda não tem nome divulgado e que deve entrar no ar nos próximos meses» (Lima, 2003).

O grupo Somzoom vem passando por grandes transformações depois de seus concorrentes. A emissora, outras épocas (2000/2001), chegou a contar com 98 emissoras afialiadas em todo país, presente em 15 estados, inclusive em São Paulo. Agora, possui apenas no Estado do Rio de Janeiro, Rádio Tropical AM, de Nova Iguaçu, como retransmissão para a região Sudeste. As demais localidades estão distribuídas pelos Estados da região Nordeste: Ceará, Rio Grande do Norte, Paraíba, Alagoas, Pernambuco, Maranhão, Piauí, Bahia; região Norte: Pará e Rondônia; Centro-Oeste: Tocantis e, como já citamos, Sudeste, Rio de Janeiro.

Contudo, a Rede Somzoom nos aponta para uma evolução do próprio grupo:

(...) A Rede Somzoom Sat está em plena expansão e cada dia são mantidos novos contatos com a finalidade de ampliar sua abrangência e cobrir cada vez mais os pontos mais distantes possíveis levando assim, não apenas a cultura musical, mas fazendo a integração entre os mais variados sotaques das regiões brasileiras. Seu público ouvinte é calculado em 35 milhões de pessoas levando-se em conta a população de cada região coberta e a torna, portanto, a maior audiência de rádio do Brasil ou quem sabe do mundo já que está também ao vivo na Internet no site www.somzoom.com (Rede Somzoom Sat, 2001).

A Somzoom Sat transmitia, incialmente, via-satélite, uma programação baseada exclusivamente na música mais tradicional do Nordeste: o forró. Os locutores falavam numa linguagem tipi- 
camente nordestina, regional. Hoje, as bandas e artistas produzidos pela gravadora Somzoom Stúdio que pertencem ao mesmo grupo e matriz dos muitos negócios do empresário Emanuel Gurgel são divulgados em toda a sua programação. A diferença dos elementos (músicas) transmitidas pela Rede Somzoom está no estilo. Antes as músicas do Nordeste tradicional eram mais divulgadas (Luís Gonzaga, Jacson do Pandero, Trio Nordestino, etc.), hoje, o estilo e a nova produção cultural do forró («Mastruz com Leite», «Cavalo de Pau», «Catuaba com amedoim», etc.):

(...) a banda de forró, o Mastruz com Leite é hoje sinônimo de sucesso. Surgida, inicialmente como uma banda de forró, o Mastruz originou um conglomerado de empresas e de negócios comandados pessoalmente pelo empresário Emanoel Gurgel. Mais do que isso, o Mastruz com Leite estabeleceu uma nova estética para a tradicional música nordestina, criou um modelo novo de operação - de reprodução - e vem promovendo uma revolução na indústria cultural do Nordeste do Brasil denominada 'Oxente! Music' - num clara alusão à baiana axé music (Pedroza, 2001, p. 3).

Outro ponto forte da Somzoom é a participação do público nordestino espalhado pelos Estados do Brasil. Essa participação ocorre por telefone, fax, e-mail. Certamente, esse ponto é considerado o mais importante, já que, além de indicar a identidade nordestina, também são potenciais consumidores dos produtos da Rede: revista, CD's de bandas de forró, shows, como as vaquejadas, etc.

Hoje, a programação da Rede Somzoom modificou-se. O forró de plástico das bandas e dos cantores produzidos pelo Somzoom Stúdio continuam sendo majoritários na programação, mas não são mais exclusivos. Os ouvintes que sintonizam uma das 98 emissoras que transmitem o sinal da rede pelo Brasil a fora podem ouvir agora músicas românticas, temas de novela e sucessos dos grupos de pagode que freqüentam os programas de TV (Pedroza, 2001, p. 3).

Neste ponto, o rádio é o meio através do qual o empresário Emanuel Gurgel promove seus negócios: venda e distribuição 
de discos (através de venda em lojas ou em sistemas alternativos como representantes, revistas, jornais e até por meio digital), promoção de shows, produção.

\section{O PERFIL DA TV DIÁRIO}

Na revista Fale! (março de 2004), produzida pela Omni Editora, sediada em Fortaleza (CE), a manchete diz: «Aldeia global: made in Ceará. Transmitindo do Ceará para o Brasil, a Rede Diário de Televisão contribui para democratizar o fluxo de informação no país». Através desta manchete, eis que surge nossa tentativa de reflexão sobre a mídia regional tendo como perspectiva o «contra-fluxo».

A TV Diário foi inaugurada no dia 01 de julho de 1998. Foi lançada para mostrar o Ceará ao Brasil. Com um vocabulário coloquial, regional e distante, em relação aos padrões de se fazer televisão, busca-se, através de uma linguagem inovadora e diferente, «traduzir a cultura e as necessidades do povo cearense» (www.verdesmares.com.br).

É a primeira emissora com uma programação 100\% cearense e, desde a sua estréia, em 98, até hoje vem mostrando o fazer da mídia local e regional. Em março de 2001 passou a ser transmitida por satélite, tendo sua programação alcance nacional e também internacional, para alguns países da América do Sul. É um dos veículos do Sistema Verdes Mares de Comunicação, o maior grupo do Estado do Ceará, que também atua nos meios de rádio, jornal, internet, além da afiliada da TV Globo, a Verdes Mares.

Na matéria da revista Fale, um boxe nos chama atenção pelos conceitos dos quais estamos abordando, o «contra-fluxo» da produção de um grupo de mídia regional fora do eixo Rio-São Paulo: «depois de chegar a todo o Brasil e até ao exterior via antena parabólica, a TV Diário começa a transmitir para outros estados também em canal aberto. É a primeira rede de televisão sediada fora do eixo Rio-São Paulo» (Firmo, 2004, p. 24).

Em princípio, quem poderia imaginar que uma televisão, com sede no Ceará pudesse transmitir para todo o Brasil, com 
cobertura em toda a região e nos principais locais do país? O que durante muito tempo não se cogitava no Nordeste, especialmente, no próprio Ceará, hoje já é realidade. E a TV Diário transformouse em Rede Diário. Além de chegar a 63 municípios em todo o Ceará, através do canal aberto (transmissão UHF), a rede já alcança também canais abertos, às cidades de São Paulo (canal 51); Carapicuíba - SP (canal 44); Vitória - ES (canal 13); São Luís - MA (canal 23); Imperatriz -MA (canal 10); Santa Inês - MA (canal 7); Ananideua - PA (canal 50); Porto Velho - RO (canal 25) e Rio Branco - AC (canal 40). A emissora ainda chega em Natal - RN; Campina Grande - PB; Caruaru - PE; Belo Horizonte - MG; Uberaba - MG; Bauru - SP; Franca - SP; Presidente Prudente - SP e Vitória - ES, através de canais por assinatura.

O que surgiu como uma televisão local, hoje se tornou uma rede nacional, que tem como prioridade à «comunicação com o público nordestino, em qualquer parte do Brasil» (Firmo, 2004, p. 25). Em entrevista, Edilmar Norões, Diretor de Programação do Sistema Verdes Mares, afirma que o público da TV Diário não é apenas o cearense, mas sim o nordestino: «Daí nós queremos ser uma estação regional. Claro que também temos público entre pessoas de outros lugares. Mas se nós tivermos o Nordeste nos vendo nesse Brasil afora, é uma fatia de público extraordinária» (Firmo, 2004, p. 25).

Dessa forma, o objetivo do Sistema Verdes Mares de Comunicação é criar uma rede de televisão regional que transmita para todo o país, a partir do Nordeste, diferente do que sempre aconteceu: «quando as programações eram criadas sobretudo no Sudeste e enviadas para outras regiões» (Firmo, 2004, p. 25). Dentro desta proposta, a TV Diário se tornou a única emissora do Nordeste a cobrir Brasília, com participação de repórteres, inclusive, ao vivo, em seus telejornais: «nós damos uma visão nordestina. Ouvindo as lideranças políticas do Nordeste, os empresários do Nordeste. Qual a posição nordestina em relação a determinados assuntos», explica Roberto Moreira, Diretor de Jornalismo da TV Diário (Firmo, 2004, p. 25). 
Além de capital federal, as equipes da TV Diário também estão presentes em outras capitais, como Salvador, Recife e Teresina. E há programas produzidos em São Paulo e Recife, principalmente, voltados ao colunismo social.

$\mathrm{Na}$ condição de «cabeça de rede», isto é, emissora em que afiliadas e retransmissoras da rede se organizam, a TV Diário ocupa um lugar privilegiado no Ceará. Ela tem hoje a maior equipe de reportagem dentre os canais de televisão locais. São 76 pessoas trabalhando na área de jornalismo. Em Fortaleza, são 16 equipes de reportagens, além de mais quatro equipes que cobrem o interior do Estado. Há, permanentemente, uma equipe na região norte, região dos Inhamus, no Vale do Jaguaribe e na região do Cariri (Sul do Ceará), que pela localização acaba cobrindo também parte de Pernambuco.

Não vamos comentar - isso daria um outro artigo - análise de conteúdo, ou estudo de recepção, sobre a programação/conteúdo da TV Diário. Nosso objetivo é registrar de maneira histórica descritiva o exemplo de uma mídia regional, que se configura no contexto do «contra-fluxo» da produção no Brasil. Porém, o formato de uma rede regional, neste caso, cearense, vai romper com alguns conceitos e dogmas de como se faz televisão. Através da linguagem («quanto mais o repórter falar nordestino, melhor» ${ }^{1}$ ), sotaques, roupas, podem-se perceber, claramente, que o profissional faz parte de uma realidade que está muito mais próximo do regional, do que o padrão, o nacional. A partir daí, o público identificase, cria relações de afetividade e, graças a tecnologia, economia vai moldando a história. É essa identidade que comenta Manuel Castells, citado por Martin Barabero: «la búsqueda de identidad -o la necesidad de reconocimiento- contribuye tan fuertemente como el cambio tecno-económico a modelar la historia».

A TV Diário está presente em todos os eventos que identificam a cultura do estado. Seja ela no campo da religiosidade - quando se transmitem, ao vivo, missas e/ou festividades em comemoraçõ-

1. Firmo, Érico. «Do Ceará para o Brasil». Entrevista do Diretor de Jornalismo da TV Diário, Roberto Moreira. Revista Fale! Fortaleza: Editora Omni, 2004. 
es as romarias de Juazeiro do Norte, terra do Pe. Cícero; missas de louvor a São Francisco das Chagas, da cidade de Canindé, outro centro de romarias do estado - no campo das festas populares vaquejadas, festas juninas, exposições agropecuárias, como a «ExpoCrato», que acontece no mês de julho; festas da cultura de massa - o «Fortal», carnaval fora de época, mês de julho, em Fortaleza, etc, etc. Neste ponto, a TV Diário acaba criando relações muito fortes com a sociedade local e regional: «tem um evento na cidade, grande, as pessoas sabem que a TV Diário vai estar lá. Nós temos um completo sentimento de cearensidade e de nordestinidade», afirma o Diretor do Jornalismo, Roberto Moreira (Firmo, 2004, p. 25).

O telespectador, seja cearense ou nordestino, acaba se identificando com o que vê na tela e isso é demonstrado pelos números de mensagens que a TV recebe todos os dias. São cerca de mil e 500 e-mails por mês, além de centenas de cartas. O curioso é o tipo de mensagem: pedidos de emprego, camisas, brindes, pedidos para localizar parentes desaparecidos, pedidos para que o sinal chegue em canal aberto, onde o serviço ainda não está disponível, pessoas que deixaram o Ceará há anos e pedem ajuda para retornar, etc., etc.

Até hoje, o recorde absoluto de participação do público da TV Diário está voltado para o campo da cultura regional. A primeira vez que a TV transmitiu a missa em comemoração ao aniversário do Padre Cícero, direto de Juazeiro do Norte, a emissora disponibilizou, nesse dia, o 0800, das quais pessoas poderiam ligar, gratuitamente, de qualquer parte do país. De acordo com dados da TV, foram mais de 40 mil telefonemas, a maior parte do estado de Minas Gerais.

A TV Diário apresenta um momento importante na pesquisa em Comunicação quando se configurou, antes, como emissora local, agora, regional, tendo como alcance o nacional e o internacional, em programação $24 \mathrm{~h}$ de produção cearense. Por ação da tecnologia e da economia, isso é possível acontecer, mexendo, um pouco, com a hegemonia de se fazer mídia, apenas, no eixo Rio- 
-São Paulo. Este fenômeno se caracteriza pelos movimentos da complexidade de como se estabelece a questão da identidade; a quebra de fronteira do tradicional para o moderno; do popular para o massivo; do local para o global, ou seja, assim como afirma Martin Barbero:

por la acción de la economía o de los medios masivos de comunicación aun las culturas más fuertemente locales atraviesan cambios que afectan a los modos de experimentar la pertenencia al territorio y las formas de vivir la identidad. Se trata de los mismos movimientos que desplazan las antiguas fronteras entre lo tradicional y lo moderno, lo popular y lo masivo, lo local y lo global. Esos cambios y movimientos resultan hoy cruciales para comprender cómo sobreviven, se deshacen y recrean las comunidades tradicionales, las nacionales y las urbanas (Martín-Barbero, 2004, p. 8).

\section{A CONTEXTUALIZAÇÃO MIDIÁTICA}

O «contra-fluxo» da produção/informação é um estudo fundamental já que, no Brasil, a informação prevalece no eixo Rio-São Paulo. Com o «contra-fluxo», vindo a informação e/ou produção cultural do Nordeste do país, caracteriza e registra uma mudança no cenário nacional. Outro ponto fundamental é a transmissão via satélite, como aborda Thompson (1999, p. 33): «Os desenvolvimentos tecnológicos recentes associados às transmissões via cabo ou satélite criaram novas oportunidades para a valorização econômica, como o pagamento das taxas de inscrição ou o uso dos cartões de crédito que permitem aos receptores a decodificação das mensagens codificadas». A Somzoom Sat e a TV Diário são exemplos de emissoras que graças ao desenvolvimento tecnológico e as transmissões satélites estão se consolidando no campo midiático.

Nossa pesquisa de doutorado, em andamento, pretende apresentar importantes contribuições contemporâneas no campo da midiologia e da comunicação em si. O «contra-fluxo» da informação/produção, através de um veículo de massa, é um exemplo ainda pouco estudado enquanto pesquisa acadêmica, ainda mais, 
tendo o veículo de comunicação no Nordeste - Estado do Ceará como ponto de análise.

A mídia brasileira se concentra na região Sudeste, no eixo Rio-São Paulo, sendo referência, modelo para todo o país. Mas quando observamos que outros grupos de mídia, de outras regiões, no nosso caso do Ceará - e sendo está região ainda em desenvolvimento - se apresenta no mercado e investindo em produções culturais, está mais do que claro que devemos nos aprofundar nestas mudanças em que o processo de globalização e as novas tecnologias permitem tais considerações.

De acordo com Thompson (1999, p. 73), devemos destacar algumas tendências centrais no desenvolvimento das indústrias da mídia: «(...) a transformação das instituições da mídia em interesses comerciais de grande escala; a globalização da comunicação; e o desenvolvimento das formas de comunicação eletronicamente mediadas». Neste ponto, a Somzoom Sat e TV Diário estariam se enquadrando no processo de globalização da comunicação já que as mesmas atingem fatias do território nacional e até internacional.

O processo de crescimento e de consolidação cada vez mais multimídia à medida que grandes corporações vão adquirindo participação crescente nos vários setores das indústrias da mídia também pode ocorrer em caráter nacional com investimento de um novo grupo de mídia, como no caso da Somzoom e TV Diário, que mantêm uma estrutura ligada a vários outros ramos da indústria da mídia, seja presente em estúdios de gravadora de CD's, investindo na indústria fonográfica para que esta divulgue suas produções culturais, como as bandas de forró; editora que investe na divulgação de matérias sobre as próprias produções culturais (agenda de shows, letras de música, entrevistas com bandas, etc.); produções 100\% regional, etc.

Estes resultados nos remota a questão histórica do próprio processo de globalização da mídia, que tem origens aos meados do século XIX. Para chegarmos a compreender e identificar a mídia na sua condição atual - investimento tecnológico e avanço territorial temos de entender antes a questão do fluxo que já havia existido 
desde o século XIX e assumia uma estrutura muito organizada e extensiva. Thompson nos indica que o desenvolvimento da comunicação no exterior, por exemplo, teve seu grande momento logo após a I Guerra Mundial, em que o rádio teve presença marcante.

(...) Depois da I Guerra Mundial, Westinghouse nos Estados Unidos e Marconi na Inglaterra começaram as primeiras experiências com transmissões radiofônicas, isto é, a transmissão de mensagens por ondas eletromagnéticas para uma indeterminada e potencialmente vasta audiência. O subseqüente desenvolvimento dos sistemas de transmissão radiofônica - o rádio a partir de 1920 e a televisão a partir dos anos 40 - foi rápido e universal (1999, p. 75).

Hoje, da mesma forma que a Televisão se apresenta de maneira nacional, o rádio também vai ao mesmo estilo, como no caso da Somzoom Sat. O mais interessante analisar é que todos os veículos, sejam televisão ou rádio, mantêm o compromisso de mostrar sua região, de fazer uma programação diferenciada, ou seja, regional, com identidade da cultura local, daí permitindo o surgimento de novos produtos culturais.

O desenvolvimento e a exploração da tecnologia se interligam de maneira muito complexa com o poder econômico, político e coercitivo. Por isso, estas empresas de mídia regionais são consideradas fortes grupos locais. De acordo com Thompson (1999, p. 75) esses interesses surgiram desde o século XIX, ou seja, «interesses comerciais, políticos e militares tiveram um papel vital na expansão das redes a cabo durante a segunda metade do século XIX». Portanto, os interesses comerciais e políticos estão pulverizados na expansão das redes via satélite, seja pelo rádio como pela televisão. O importante é transmitir a programação, ter espaço para isso. Como vai ser a grade da programação, por exemplo, vai depender da linha e dos objetivos de cada empresa.

5 CONSIDERAÇÕES FINAIS

A Somzoom Sat e a TV Diário despontam para o se fazer mídia, fora do eixo Rio-São Paulo, buscando marcar presença no 
campo comercial. Se formos analisar pelos segmentos que as compõem, evidenciamos o desenvolvimento de cada grupo. O rádio, por exemplo, permite a estratégia de divulgar novas produções culturais. Thompson (1999, p. 76) no livro A mídia e a modernidade, historicamente, nos remete a entender que:

o potencial comercial e a importância estratégica do rádio, governos e instituições militares americanas, britânicas e alemães exerceram um papel ativo em seus desenvolvimentos. A evolução subseqüente dos sistemas de transmissões radiofônicas se realizou dentro de estruturas que variavam grandemente de um contexto nacional para o outro e que negociações - entre os interesses comerciais das indústrias da mídia, de um lado, e as preocupações políticas com a regulamentação, o desenvolvimento e o controle de novos meios de comunicação, de outro (1999, p. 76).

Portanto, a Rede Somzoom Sat é exemplo de uma evolução tecnológica e midiática. E Thompson (1999, p.76) ainda nos alerta de que este «ambiente da mídia que nos foi legado pelos desenvolvimentos dos séculos XIX e Xx ainda sofre hoje contínuas transformações».

A TV Diário vem complementar as novas formas de ação e de interação. Thompson (1999, p. 77) cita que:

os novos tipos de relacionamentos sociais - formas que são bastante diferentes das que tinham prevalecido durante maior parte da história humana. (...) faz surgir uma complexa reorganização de padrões de interação humana através do espaço e do tempo. Com o desenvolvimento dos meios de comunicação, a interação se dissocia do ambiente físico, de tal maneira que os indivíduos podem interagir uns com os outros ainda que não partilhem do mesmo ambiente espaço-temporal.

Portanto, essas estruturas de mídia regional, tendo o «contra-fluxo» como perspectiva permitem uma nova forma de interação tanto no sentido humano como no sentido de consumo das produções culturais. 
Essa relação cultura e mídia surgiram na compreensão em que os gerentes das emissoras de rádio e canais de televisão ou os pesquisadores de mercado fazem idéia de como o povo é ou de que o povo gosta ou necessita. A estratégia é integrar o público através daquilo que o identifica na programação: seja através do forró, do CD, dos shows, das festas populares, do telejornal local/regional, do programa de humor, etc., o público se vê na TV ou no rádio. 
ANEXO

PERFIL DO GRUPO EDSON QUEIROZ

Holding: Queiroz Comércio e Participação S/A.

Distribuição de GLP: Nacional Gás Butano Distribuidora Ltda. Paragás Distribuidora Ltda.

Mineração, Distribuição de águas, Minerais e Refrigerantes: Indaiá Brasil Águas Minerais Ltda. Minalba Alimentos e Bebidas Ltda. Midol - Mineração Dolomita Ltda.

Metalurgia: Telecomecânica Esmaltec Ltda. Esmaltec S.A. Telecomunicações: Televisão Verdes Mares Ltda. Tv Verdes Mares, Fortaleza. Rádio Tamoio, Rio de Janeiro. Recife FM, Recife. TV Diário. Editora Verdes Mares Ltda. Rádio Verdes Mares Ltda. Jornal Diário do Nordeste. 810 Verdinha, Fortaleza. FM 93, Fortaleza.

Agropecuária: Esperança Agropecuária e Indústria Ltda.

Agroindústria: Cascaju Agroindustrial S/A.

Ramo Imobiliário: Nacional Investimentos e Participações Ltda. Queiroz Empreendimentos Imobiliários Ltda.

Instituições sem fins lucrativos: Fundação Edson Queiroz (Mantenedora da Universidade de Fortaleza - Unifor).

Fonte: Revista Fale! Fortaleza, março de 2004. 


\section{REFERÊNCIAS BIBLIOGRÁFICAS}

BAUdRillard, Jean. A sociedade de consumo. Lisboa: Edições 70, 1995.

BRUNER, José Joaquim. Globalización, cultura y posmodernidad. Santiago: FCE, 1998.

DIÁRIO DO NORDESTE. TV Diário passa a ser transmitida via satélite para todo o Brasil. Fortaleza, 21 de março de 2001, caderno Cidade.

FADUL, Anamaria. "A internacionalização da mídia brasileira». Revista Comunicação e Sociedade. N. ${ }^{\circ}$ 30, PósCom/UMESP, São Bernardo do Campo, 1998.

Firmo, Érico. «Do Ceará para o Brasil». Revista Fale! Fortaleza, Editora Omni, março de 2004.

Ianni, O. A socidedade global. Rio de Janeiro: Civilização Brasileira, 1992.

— Teorias da globalização. Rio de Janeiro: Civilização Brasileira, 1995.

MARTín-BARBERo, Jesús. «Medios y culturas en el espacio latinoamericano», en Revista de Cultura Pensar Iberoamérica. Número 6, maio i agosto de 2004. Disponível em www.campusoei.org/pensariberoamerica/ric06a05.htm. Acesso em 19/06/2004.

MATTOS, Laura. «Festa do interior. TVs locais crescem com empurrão de anunciantes que passam a investir mais nos mercados regionais». Folha de S. Paulo, 14 de janeiro de 2003.

Lima, Rinaldo. Estação Sat. Entrevista concedida à Maria Érica de Oliveira Lima. Março de 2003.

Oliveira Lima, Maria Érica de. «Rede Bahia de Comunicação: um exemplo de mídia regional». Trabalho apresentado na mesa 
«Grupos Midiáticos Regionais» no VIII Colóquio Internacional de Comunicação para o Desenvolvimento Regional - Regiocom 2003, Unimar, Marília (SP).

Pedroza, Ciro José Peixoto. Mastruz com leite for all: folkcomunicação ou uma nova indústria cultural do Nordeste brasileiro. INTER$\mathrm{COM}$ - Sociedade Brasileira de Estudos Interdisciplinares da Comunicação, XXIV Congresso Brasileiro da Comunicação, Núcleo de Pesquisa Folkcomunicação, Campo Grande, CD Rom INTERCOM, 2000.

Thompson, John B. A mídia e a modernidade: uma teoria social da mídia. Petrópolis: Vozes, 1999.

www.verdesmares.com.br

www.somzoomsat.com 